\title{
A religião como meio de inclusão e de exclusão nas corporaçóes de ofício de Estrasburgo (1681-1789)*
}

Hanna Sonkajärvi

\begin{abstract}
RESUMO
O artigo propõe uma análise das dinâmicas de inclusão e de exclusão construídas a partir do pertencimento religioso, ou confessional nas corporaçôes de ofício em Estrasburgo no século XVIII. Na sociedade do Antigo Regime, a religião fazia parte - assim como o status social, os vínculos familiares, o gênero, o patronato e os meios financeiros, a língua e os direitos de burguesia - dos fatores decisivos para incluir ou excluir os estrangeiros do acesso aos recursos econômicos, políticos ou sociais das localidades. A construção e a preservação das fronteiras religiosas são examinadas a partir do exemplo dos marceneiros e dos barqueiros na cidade multi-confessional de Estrasburgo.
\end{abstract}

Palavras-chave: inclusão, exclusão, religião, corporaçóes de ofício.

\begin{abstract}
This paper discusses the importance of religion as a factor influencing the inclusion and exclusion of foreigners from the guilds in the city of Strasbourg, in the eighteenth century. In the Ancien Regime society, religion - as well as social status, family ties, gender, sponsorship and financial reserves, language and rights of the bourgeoisie - was a part of the decisive factors to include or exclude the foreigners on the access to economic, political or social resources of the cities. In this paper, the construction and preservation of religious boundaries are examined through the examples of carpenters and boatmen guilds in the multi-confessional city of Strasbourg.
\end{abstract} Keywords: inclusion, exclusion, religion, guilds.

\footnotetext{
* O Comitê Editorial agradece aos professores Anderson José Machado de Oliveira, Beatriz Catão Cruz Santos e Cláudia Regina Andrade dos Santos a oportunidade de oferecer aos leitores de Topoi. Revista de História este artigo de Hanna Sonkajärvi. Trata-se da palestra que a autora proferiu em 8 de setembro de 2011, no âmbito das atividades acadêmicas promovidas pelo Programa de Pós-graduação em História da Universidade Federal do Estado do Rio de Janeiro (Unirio) e o Grupo de Estudos em História da Igreja no Brasil (Ecclesia-CNPq).
} 


\section{Introdução}

No dia 30 de setembro de 1681, as tropas francesas entram na cidade alsaciana de Estrasburgo que deixava de ser uma cidade livre do Império Germânico para se tornar uma cidade livre real francesa. A capitulação concedida por Luís XIV à antiga cidade do Império garantirá a proteção de suas instituiçôes, sua integridade territorial, assim como o domínio das jurisdiçóes ${ }^{1}$ rurais e da ponte do Reno. Depois de 1681, a língua e a cultura alemãs são confrontadas aos costumes dos imigrantes de língua francesa, permanecendo, no entanto, majoritárias. Além dos luteranos, calvinistas, católicos e judeus, encontram-se, cotidianamente, diferentes grupos confessionais e religiosos ${ }^{2}$. O pertencimento religioso, ou confessional representava um fator importante para incluir, ou excluir o indivíduo de uma comunidade. Ainda que a exclusão econômica fosse, em muitos casos, justificada pelo argumento confessional, a religiáo não era, de maneira alguma, a única motivaçáo para a inclusão ou a exclusáo. Na maioria das vezes, o pertencimento religioso servia, sobretudo, de pretexto para um conflito de ordem econômica. Dessa forma, as fronteiras confessionais se manifestavam no mundo do trabalho permitindo a exclusão dos católicos de certas corporaçôes e a sua marginalização no interior de outras. Neste artigo propomos uma análise dessas relaçôes de poder que fundam as distinçôes entre "nós" e os "outros" nas corporaçôes de ofício de Estrasburgo sob a dominação francesa ${ }^{3}$.

Em 1777, ou seja, apenas doze anos antes da Revoluçáo Francesa, um fabricante de bordados ${ }^{4}$ originário de Paris, chamado Guillaume François Retaillon, comparecia diante do magistrado de Estrasburgo para manifestar o seu desejo de instalar na cidade - junto com seu associado Fantet, comerciante-fabricante de Lyon - sua fábrica de tecidos de seda, sediada em Kehl. Retaillon trabalhara desde 1773 no Palatinado, posteriormente em Kehl, e desejava retornar à França ${ }^{5}$. Retaillon e Fantet dirigem-se, entáo, à Guilda ${ }^{6}$ do Espelho, solicitando serem recebidos como comerciantes-fabricantes e a obtenção do "direito de burguesia" . Mas, Retaillon encontra bastante resistência. Os fabricantes de bordados se opóem à sua admissão, alegando que ela destruiria os vínculos tradicionais da profissão com as confrarias dos Estados alemães e dos países do Norte. Retaillon se submete então ao Conselho dos XV do Magistrado. Mas, a direção da guilda, integrada por mestres eleitos pelos seus membros, se dirige a ele somente em alemão, impedindo assim qualquer comunicação. Ultrajado pela hostilidade do Magistrado, Retaillon acusa-o de conceder tratamento pior aos súditos do Rei do que aos estrangeiros:

Se os estrasburgueses e todos os alsacianos são livres para serem recebidos em todos os corpos e comunidades de artes e de ofícios, não somente em Paris, mas também em todas as cidades do reino ${ }^{8}$, por que então os parisienses seriam excluídos do direito de retaliação e de reciprocidade na cidade de Estrasburgo, direito de todos os outros súditos do Rei? Por que os estrasburgueses recebem e atribuem esse direito aos estrangeiros, alemáes e outros sem a menor dificuldade, cotidianamente, em todas as corporaçóes da comunidade, em detrimento dos súditos do Rei, excluindo-os??

O exemplo de Retaillon mostra como as corporaçóes de ofício de Estrasburgo excluíam os franceses ou, principalmente, os católicos, de suas fileiras. Em quais situaçôes a definição de estrangeiro tornava-se um fator importante para o acesso às corporaçóes? Quais eram os argumentos usados pelos dois lados e quais eram as modalidades de inclusão e de exclusão? Essas são as questóes que tentaremos responder aqui. Começaremos por examinar as tradiçóes do sistema corporativo estrasburguês à época da cidade livre imperial, as quais serviram de argumento contra a introdução de franceses e católicos na cidade. Em um segundo momento, analisaremos de que maneira os recém-chegados eram incluídos ou excluídos do acesso às guildas, mas também no interior das próprias corporaçóes. Do mesmo modo, mostraremos de que forma alguns deles podiam estabelecer, com o apoio da Coroa, estruturas paralelas, ou seja, guildas "francesas". 


\section{O papel das corporaçóes de ofício na inclusão e na exclusão dos estrangeiros} 1.1. O sistema de corporaçóes de ofício estrasburguês

Desde 1482, as diferentes profissóes estrasburguesas eram distribuídas em 20 corporaçôes, chamadas Tribus, ou Zünfte. Algumas delas englobavam uma única profissão: a Guilda dos Padeiros; a dos Açougueiros; a dos Jardineiros; a dos Pescadores. Na maioria dos casos, profissóes similares eram agrupadas em uma única corporação. Mas, havia também o caso de algumas extremamente heterogêneas como a Guilda do Espelho (Spiegel) que agrupava, além dos comerciantes, confeiteiros, chapeleiros, fabricantes de botóes, de pentes, de bolsas, de escovas e de agulhas ${ }^{10}$.

O pertencimento a uma corporação de ofício era obrigatório para todo burguês. Havia três categorias de membros: os Zudiener, os Leibzünftige e os Geldzünftige. Os indivíduos ligados às artes liberais, os membros das universidades, os médicos, os juristas e os membros das famílias que ocupavam a Magistratura, como também os novos burgueses que ainda não integravam nenhuma comunidade de profissão, deveriam inscrever-se numa corporação de ofício de sua escolha ${ }^{11}$. Eles eram chamados Zudiener (agregados da guilda), diferentemente dos Leibzünftige (membros da guilda em funçáo de sua profissão). Em razão disso, era possível encontrar os graduados em Direito, tanto na Guilda da Âncora quanto na dos Pedreiros ${ }^{12}$. Também era possível pertencer a duas guildas ao mesmo tempo ${ }^{13}$. As condiçôes de admissão variavam segundo a corporação de ofício. Em geral, o celibato e o tempo de oito a doze anos de vida itinerante como "companheiro"14 eram exigidos para os candidatos ao estatuto de mestre. A duração da "condição de companheiro" 15 era reduzida a dois anos para os filhos de mestres. Os estrangeiros na cidade que casassem com a filha ou com a viúva de um mestre seriam admitidos depois de uma permanência de dois anos na casa de dois mestres sucessivos. Quanto aos artesãos (ou "companheiros") casados, era necessário esperar ainda doze anos, depois de terem se tornado mestres, para contratarem aprendizes ou artesãos ${ }^{16}$.

\subsection{Defesa dos vínculos alemães e defesa do sistema corporativo}

Estrasburgo pertencia ao circuito dos "companheiros" alemães. Numerosos alemães se instalavam na cidade e adquiriam o "direito de burguesia". Os guardas da cidade deviam garantir que somente os indivíduos com um passaporte e com uma declaração expedida pelo seu último mestre fossem admitidos na cidade. Aqueles que não encontravam trabalho deviam sair da cidade em três dias ${ }^{17}$. Algumas corporaçôes de ofícios hospitaleiras (die geschenkten Handwerker) forneciam sustento aos "companheiros” estrangeiros que não encontravam trabalho na cidade ${ }^{18}$.

O aprendizado nas guildas de Estrasburgo tinha uma boa reputação; e em certas cidades alemãs, os jovens postulantes a um ofício, que passavam por Estrasburgo, podiam ter direito a uma diminuição do seu tempo de aprendizagem. A análise de François-Joseph Fuchs dos processos, entre os anos de 1716 a 1724, da Corporação da Perna de Pau ${ }^{19}$ (Zunft zur Stelz) ${ }^{20}$ dá uma boa ideia da origem dos aprendizes e dos artesãos estrangeiros ${ }^{21}$ nessa renomada corporação de Estrasburgo. Essa guilda agrupava as principais profissôes artesanais, entre as quais, ourives, vidraceiros, encadernadores, assim como pintores e impressores. Aprendizes e companheiros eram recrutados em um vasto espaço geográfico, de norte a sul, de leste ao oeste: na Dinamarca (em Aalborg); na Áustria-Hungria; na Polônia (em Gdansk e Wroclaw); na Suíça e até no sul da França (em Marselha e em Montpellier), assim como na Bélgica (em Liege e em Bruxelas) e nos Países Baixos (em Utrecht). Vários deles vinham de cidades tão célebres - do ponto de vista do trabalho de seus artesãos - quanto Estrasburgo: Augsburgo, Nurembergue, Munique, Dresden e Colônia ${ }^{22}$.

Como as corporaçóes formavam a base do sistema político, social e econômico da cidade, náo é muito surpreendente que o Magistrado - e mesmo o representante do Rei, o Pretor Real ${ }^{23}$ - tenham se pronunciado a favor delas todas as vezes que a sua existência, ou a sua composição, foram ameaçadas. Neste senti- 
do, quando o Conselho de Estado promulgou a sentença de 25 de março de 1755 prevendo que qualquer pessoa, tendo executado sua "obra-prima" ${ }^{24}$ numa cidade do reino, devia ser admitida pelas guildas de Estrasburgo, o Magistrado e as corporaçóes protestaram com sucesso, evocando o tratado de capitulaçáo, pelo qual a "república" de Estrasburgo tinha se submetido, por sua livre vontade, ao Rei da França ${ }^{25}$.

\section{Os jogos de inclusão e de exclusão}

\subsection{A introdução de novas profissóes e o acesso dos católicos às guildas}

A atitude frente aos recém-chegados variava muito segundo a corporação. Entretanto, os artesãos imigrados do Reino não eram apenas rejeitados pelas corporaçôes de Estrasburgo; em parte, eles também se recusavam a entrar nas corporaçóes de ofício da cidade regidas pelos princípios germânicos. No século XVIII, certas corporaçóes foram afetadas pela diminuição do número de seus membros, como a dos barqueiros, após as dificuldades provenientes da navegação no Rio Reno; outras corporaçóes, ao contrário, duplicaram seus efetivos, como a dos alfaiates costureiros, que passou de 152 integrantes, em 1681, para 369, em 1789 (incluindo as costureiras). Após a chegada dos franceses, algumas profissões novas se estabeleceram em Estrasburgo: fabricantes de perucas e cabeleireiros, mestres de armas, ou de dança ${ }^{26}$. Outras profissões se diversificaram. Nesse caso, em razão da obrigação da "obra-prima”, corporaçôes concorrentes foram criadas, como a dos "marceneiros franceses de Estrasburgo". Seleiros e padeiros também se dividiram entre corporaçóes "alemâs" e "francesas".

A proporçáo de católicos permaneceu desigual, conforme as guildas e segundo as comunidades de ofício. Nas profissôes tradicionais, os recém-chegados experimentaram mais dificuldades de instalação. Em 1789, a proporção de católicos era mais elevada na Guilda dos Gastrônomos ${ }^{27}$ (50\%) e na dos Pedreiros (45\%), enquanto permanecia muito baixa entre os jardineiros (8\%), os tanoeiros (10\%) e na Guilda da Flor que agrupava os açougueiros e os salsicheiros $(9 \%)^{28}$. Várias corporaçóes, entretanto - curtidores; seleiros alemães; fabricantes de carroças e de rodas ${ }^{29}$; fabricantes de pentes; fabricantes de escovas e de meias; tintureiros; moleiros; padeiros; fabricantes de óleo e de cerveja - permaneciam inteiramente nas mãos dos protestantes. Por outro lado, certos ofícios novos, como os fabricantes de tapetes $(90 \%)$, os gesseiros (100\%), os douradores (100\%) e os fabricantes de selas franceses (100\%) eram dominados pelos imigrados vindos da Alsácia, ou do outro lado do maciço do Vosges ${ }^{30}$.

A importância da religião como fator de exclusão nas corporaçôes de ofício não tinha, aliás, nada de especial em Estrasburgo. Nas cidades alemãs, onde o "direito de burguesia" - e com ele o acesso às profissóes - era aberto frequentemente apenas aos que professavam a mesma fé (Religionsverwandte), o pertencimento à "falsa" religiáo constituía um obstáculo grave ${ }^{31}$. Assim, em Francfort-sur-le-Main, o Magistrado e as corporaçóes tentaram recusar o acesso aos imigrantes católicos. Um processo, contudo, levado em 1766 à Corte suprema do Império, se encerrou com uma sentença favorável aos católicos. No entanto, na prática, ela não foi aplicada ${ }^{32}$.

\subsection{O desenvolvimento de estruturas paralelas no interior de uma guilda: marceneiros alemães e marceneiros franceses.}

A anexação pela França da cidade de Estrasburgo e a instalação do Bispado, do clero católico, da administração real, do exército e da nobreza francesa foram acompanhadas por uma corrente migratória de artesãos católicos. Na sua maioria, eram indivíduos que exerciam profissóes ligadas à construção e à fabricação de objetos de luxo. Fabricantes de perucas, cabeleireiros, fabricantes de selas, mestres de dança, restauradores e músicos se estabeleceram na cidade.

Ao mesmo tempo em que a imigração de artesãos alemáes continuava, a construção de casernas, a restauração do mobiliário das igrejas adaptadas para o culto católico ${ }^{33}$ e a edificação de prédios 
representativos para as novas administrações eclesiásticas ${ }^{34}$ e nobres atraía certo número de marceneiros, chamados de "franceses" na cidade ${ }^{35}$. Esses estrangeiros exerciam sua profissão, sem antes terem executado uma "obra-prima" no local e sem pertencerem à corporação. Tendo sido contratados pelo exército ou pelo bispo, trabalhavam em condiçóes privilegiadas escapando ao controle do Magistrado e da Corporação dos Fabricantes de Carroças ${ }^{36}$ e também às taxas ordinárias. A presença deles suscitava a hostilidade dos mestres marceneiros de Estrasburgo que os qualificavam de Pfuscher ${ }^{37}$, ou profissionais incompetentes ${ }^{38}$. Entre esses marceneiros encontravam-se, tanto artistas qualificados de alto nível, como também artesáos não qualificados. Na cidade de Estrasburgo e nos conventos foram organizadas "verdadeiras redes de empresas clandestinas" 39 - agrupando imigrantes de língua francesa, assim como católicos de origem alemã - que escapavam ao controle das corporaçóes.

Numerosas queixas dirigidas pela Corporação dos Marceneiros de Estrasburgo resultavam em advertências pouco eficazes. Portanto, com o objetivo de excluir os artesãos franceses que começavam a se estabelecer solidamente graças à demanda da Igreja e dos administradores reais, o Magistrado começou a persegui-los individualmente. Os marceneiros de Estrasburgo procuravam afirmar sua singularidade e excluir os portadores das novas modas barrocas, através da regulamentaçáo da "obra prima". Evocando as tradiçóes germânicas, eles se recusavam a validar o "exame de mestria" obtido em outras cidades do reino. Dessa forma, no ano de 1698, eclodiu um conflito entre os marceneiros de Estrasburgo e os seus confrades franceses, no momento em que o marceneiro francês, Pierre Lizant, foi interpelado diante do Conselho dos XV pela Corporação dos Marceneiros ${ }^{40}$. Lizant informou ao Magistrado que ele tinha realizado uma "obra-prima" em Rouen ${ }^{41}$ e acusou a corporação estrasburguesa de impedir os marceneiros franceses de exercerem seu ofício na cidade. Aproveitando-se dessa ocasião, o Magistrado ordenou o confisco dos instrumentos de trabalho desses "falsos artesãos franceses", que não tinham executado uma "obra-prima" local ${ }^{42}$.

Empenhados em regularizar sua situação, os marceneiros franceses se ofereceram então para a construção do altar da capela em honra a São Lourenço na catedral de Estrasburgo. Eles exigiram o direito de serem aceitos como mestres ainda que tivessem "aprendido o seu ofício na França e que, em razão disso, não estivessem familiarizados com as técnicas alemâs" "³. Graças à proteção do Senhor de la Fond, Intendente da Alsácia, e do Síndico Real ${ }^{44}$ de Obrecht, eles obtiveram a permissão de "realizar uma obra-prima à maneira francesa que em nada deixaria a desejar à obra-prima alemâ”. Procurando garantir o apoio das autoridades eclesiásticas, se ofereceram para construí-la gratuitamente. Sem esperar a regularização de seu estatuto pessoal, organizaram-se em uma corporação e encomendaram, na capela de São Lourenço, uma missa pelo dia de Santa Ana, padroeira de sua confraria ${ }^{45}$. Os trabalhos demoraram muito e acabaram provocando reclamaçóes do Grande Coro da Catedral. Por fim, em 1710, o altar foi apresentado ao júri para o "exame de mestria". De início, apenas quatro marceneiros se apresentariam frente ao júri, mas oito acabam prestando o exame ${ }^{46}$. Entretanto, a "obra-prima” apresentada não correspondia às exigências da Corporação dos Marceneiros estrasburguesa, e, nesse contexto, começou a circular a informação de que apenas um deles teria, de fato, trabalhado na execução da obra ${ }^{47}$. Em razão disso, os marceneiros de Estrasburgo se recusaram a reconhecer o altar como "obra-prima”, argumentando que se eles aceitassem esses franceses "tão pouco competentes", nenhum artesão dos Estados alemáes procuraria, daí em diante, a cidade. Sugeriram então que os franceses fundassem sua própria confraria. Eles se agrupariam numa corporação distinta da local, ainda que com os mesmos estatutos traduzidos para o francês e registrados pelo Magistrado ${ }^{48}$. Para esse último, a principal vantagem de tal solução era a permanência dos artesãos franceses sob a jurisdição do Conselho dos XV do Magistrado. Assim foi criada a Comunidade dos Mestres Marceneiros Franceses da cidade de Estrasburgo ${ }^{49}$.

Apesar da organizaçáo da confraria francesa, permaneceu intacta a necessidade de demarcar uma fronteira entre as duas comunidades; de estabelecer uma distinção entre dois tipos de "exames de mestria" e de definir os "profissionais incompetentes" (gâte métiers) $)^{50}$. Em resposta à demanda dos marce- 
neiros de Estrasburgo, ficou decidido pelo Conselho dos XV, em 1740, que a comunidade dos mestres franceses só poderia aceitar aprendizes franceses, ou artesãos formados por um mestre francês ${ }^{51}$. Entretanto, o pertencimento se definia, de fato, menos em função da origem geográfica, ou da língua, do que em razão da religião. De 1728 a 1780, entre os 48 companheiros que executaram sua obra-prima entre os mestres "franceses", somente dez tinham um nome francês ${ }^{52}$. Além disso, desde 1703, os protocolos da comunidade passaram a ser redigidos em alemão. De maneira geral, a comunidade francesa era constituída por católicos, sendo a maioria alemã, enquanto que a antiga forma de aprendizado permanecia protestante, ainda que com uma minoria católica. Graças ao crescimento da população católica e às regras de inscrição, inicialmente menos rígidas, a formação francesa atraiu mais artesãos do que a antiga formação que parece ter sofrido uma diminuiçáo no número de seus companheiros. A existência de uma comunidade francesa não impediu, aliás, que certos imigrantes franceses continuassem a trabalhar fora do sistema corporativo ${ }^{53}$. Pelo seu lado, a comunidade francesa tentou rapidamente restringir o número de novos mestres, impondo critérios mais rígidos para a execução da obra-prima.

Esses critérios e aqueles estabelecidos para o acesso à formação nas duas comunidades acabaram se aproximando de tal forma - graças principalmente a uma adaptação recíproca dos modos e técnicas de trabalho - que as duas comunidades tentaram uma fusão em 1750. Incentivados pelo Pretor Real e motivados pelas dificuldades contínuas relacionadas à divisão do mercado de trabalho, os 67 mestres alemães e os 50 mestres franceses acabaram concordando em constituir uma única corporação ${ }^{54}$. Mas, essa tentativa fracassou em razão da questão religiosa e das dívidas da comunidade francesa ${ }^{55}$. Finalmente, as duas corporaçóes acabaram por se reunir em 1781, quando o permitiu a trégua religiosa e a reintrodução de casamentos mistos entre luteranos e católicos ${ }^{56}$.

\section{Marginalização no interior da guilda: os barqueiros católicos}

No seu estudo sobre a antiga diocese de Estrasburgo, Louis Châtellier apresentou uma estatística segundo a qual os burgueses católicos não teriam ocupado, em relação aos protestantes, uma posição inferior no plano sócio-profissional. Segundo o autor, as categorias mais elevadas, os comerciantes, ou ainda os administradores e os profissionais liberais, eram recrutados de preferência entre os católicos. Neste sentido, ele conclui que:

Nada, na origem geográfica nem na atividade profissional nem no poder econômico distinguia verdadeiramente os novos burgueses católicos dos protestantes. Tal situação, não facilitava muito a integração dos recém-chegados na sociedade estrasburguesa? ${ }^{37}$

Mas, a igualdade de estatuto, apenas, traduzir-se-ia automaticamente em uma igualdade de tratamento?

A mistura religiosa no interior das guildas podia, em alguns contextos, resultar em conflitos entre membros das duas confissóes, luterana e católica. A Alternativa (regra promulgada pelo Rei, em 1685, que ordenava que os ofícios fossem distribuídos igualmente entre católicos e luteranos) praticamente não se aplicava às corporaçóes que continuavam a excluir os imigrantes franceses e católicos. A discriminação podia se explicar, segundo os próprios atores históricos, pelo pertencimento religioso. Um exemplo desse tipo de exclusão é fornecido pelo conflito entre membros luteranos e católicos da Corporação dos Barqueiros de Estrasburgo.

Em julho de 1766, os barqueiros da cidade elegeram, nas suas fileiras, aqueles que exerceriam o Umgang, prática que consistia em distribuir os contratos de transporte de mercadorias entre os membros da corporação de ofício, segundo uma ordem previamente estabelecida ${ }^{58}$. O direito de Umgang era obtido pelo critério da antiguidade e concedido somente aos barqueiros bem sucedidos, possuidores de "grandes" barcos - o que era definido pela própria guilda. Os barqueiros excluídos deveriam se contentar com o transporte de pessoas, ou com empreitadas ocasionais, o que era muito menos rentável. 
O objetivo dessa prática - que parece ter sido introduzida em meados do século XVII ${ }^{59}$, a exemplo dos barqueiros de Bâle - era restringir a concorrência entre os membros de uma corporação de ofício e contribuir dessa forma para manter os preços em alta. Em razão disso, ela gerou inúmeras reclamaçóes, tanto por parte dos barqueiros excluídos, quanto pelos mercadores, clientes dos barqueiros ${ }^{60}$.

O Conselho Soberano da Alsácia (tribunal de justiça, de primeira e de segunda instância, sob cuja alçada encontrava-se Estrasburgo) recebeu uma apelação de seis barqueiros católicos descontentes por terem sido preteridos no Umgang. Seis luteranos e somente dois católicos tinham sido eleitos no lugar de oito barqueiros mortos. O Conselho Soberano decidiu, em 25 de fevereiro de 1767, anular a eleiçáo de julho de 1766 e ordenou que uma nova eleição fosse realizada para que se escolhessem, entre os barqueiros do segundo escalão, o mesmo número de católicos e de luteranos em substituição aos oito barqueiros do primeiro escalão; e condenou os barqueiros eleitos a pagarem as despesas do processo ${ }^{61}$. O Magistrado de Estrasburgo protestou: a Alternativa só era aplicável a eleiçóes para membros da Magistratura $^{62}$. Ele conseguiu, entretanto, uma vitória parcial, pois seu monopólio sobre o controle das artes e ofícios foi mantido, ficando decidido que o Conselho Soberano da Alsácia não poderia receber apelaçóes desse tipo, enquanto o Rei náo o tivesse instituído definitivamente. O problema ressurgiu em 1793, mas foi levado ao Magistrado que decidiu contra a apelação dos querelantes ${ }^{63}$. Na época, havia 24 barqueiros no Umgang, dos quais somente quatro eram católicos ${ }^{64}$.

\section{Conclusão}

A leitura de todos esses episódios sobre a defesa das estruturas corporativas e sobre a exclusão de estrangeiros poderia nos levar a concordar com a opiniáo tradicional de que as corporaçóes de ofício constituíram um fator de imobilismo e um freio ao desenvolvimento capitalista ${ }^{65}$. Mas, a realidade se mostrou mais complexa e as fronteiras entre incluídos e excluídos das diferentes corporaçóes de ofício mais permeáveis. De fato, os indivíduos podiam mudar de guilda, podiam ser excluídos delas, ou serem admitidos, e ainda assim permanecerem marginalizados em seu interior. Enfim, eles podiam também ter interesse em não aderir a uma corporação, ou em formar corporaçóes concorrentes.

As guildas de Estrasburgo sabiam tirar proveito dos interesses divergentes do Estado e da cidade para assegurarem sua existência, mostrando-se também capazes de se adaptarem às novas circunstâncias provocadas pela chegada dos imigrantes, principalmente dos franceses. Apoiadas pelo Magistrado e pelo Pretor Real, as corporaçóes de ofício continuaram a existir, apesar da presença de estruturas paralelas - como no caso dos marceneiros e dos fabricantes de perucas -, dos chambrelans ${ }^{66}$ e da divisão no seio da guilda, como vimos com os barqueiros. As modificaçôes do sistema corporativo aparecem assim como o resultado de um processo contínuo de contestação, pelos indivíduos, das regras existentes dentro e fora das corporaçóes de ofício. Campo de estatutos e de jurisdiçóes concorrentes, a cidade oferecia aos indivíduos e aos grupos, a possibilidade de se aproveitarem das "brechas" ${ }^{37}$ assim criadas.

Sobre os mecanismos de inclusão e de exclusão, duas observações são necessárias. A primeira é que o estabelecimento dos estrangeiros parece ter sido mais fácil nos novos ofícios e nos ofícios em expansão (como na construção), onde os recém-chegados souberam aproveitar os nichos abertos pela coexistência de diferentes autoridades na cidade. Em contrapartida, os ofícios em declínio (como o dos barqueiros), ou ainda os ofícios tradicionalmente bem estabelecidos, eram especialmente hostis aos recém chegados, "franceses" ou católicos. As guildas desempenhavam, portanto, um papel significativo na divisão do trabalho. A segunda observação - que parece plausível, a partir do exemplo dos marceneiros - é de que, nesse caso particular, a exclusão se fundamentou numa pretensa ausência de "competência" dos "franceses". Ora, "competência" é uma noção socialmente construída e, consequentemente, constantemente redefinida. Deborah Simonton demonstrou como, no contexto de Aberdeen, no século XVIII, essa mesma noçáa de competência (skill) foi empregada para excluir as mulheres de certos ofícios ${ }^{68}$. 
No caso dos marceneiros de Estrasburgo, percebe-se a aproximação dos estilos e dos critérios de admissão, na medida em que a fronteira - e dessa vez, uma fronteira fundada na divisão confessional - foi estabelecida entre as duas corporaçóes.

Em seu artigo sobre o Edito de Nantes na Alsácia, Christian Pfister observa que "o antagonismo religioso era fundamental: a oposição entre as pátrias, menor” ${ }^{69}$. Um argumento parecido é utilizado por Étienne François que, no seu estudo sobre a cidade alemã de Coblence no século XVIII, constata que as fronteiras religiosas foram, até o fim do século XVIII, muito mais difíceis de ultrapassar do que as fronteiras de Estado, ou as fronteiras naturais ${ }^{70}$. Os casos que apresentamos aqui parecem confirmar essa constatação. A exclusão econômica foi frequentemente justificada pelo argumento confessional. O pertencimento à religiáo protestante, ou à católica podia determinar, não somente o acesso à corporação, mas também o lugar do indivíduo no interior da organização. Finalmente, como mostra o exemplo dos "marceneiros franceses" (que, em grande parte, não eram do reino, mas católicos originários dos Estados alemães), o pertencimento religioso podia ser utilizado para sustentar a construção e a manutenção de fronteiras entre as estruturas paralelas das corporaçôes "alemãs" e "francesas".

\title{
Tradução: Cláudia Regina Andrade dos Santos Revisão técnica e edição: Maria Aparecida Rezende Mota
}

\begin{abstract}
Notas
${ }^{1}$ No original bailliage. Circunscrição criada no século XIII na França a partir das funçôes do bailio, funcionário do Rei, cujas atribuiçóes eram bastante extensas nos domínios administrativos, judiciários, financeiros e militares. O número de bailios cresceu progressivamente durante os séculos XIV e XV. Em decorrência do processo de centralização e da especialização administrativa, os bailios perderam muito de seu poder, mas as bailliages se conservaram como divisóes judiciárias e administrativas. Cf. MOURRE, Michel. Dictionnaire encyclopédique d'Histoire. Paris: Larousse-Bordas, 1998. Nota do Tradutor.

${ }^{2}$ Por volta de 1750, a população luterana tornou-se inferior à população católica. Às vésperas da Revolução, a cidade contava com 25.300 a 25.700 católicos e 22.200 a 22.500 luteranos numa população total de 48.500 pessoas. Cf. DREYER-ROOS, Suzanne. La Population strasbourgeoise sous l'Ancien Regime. Strasbourg: Istra, 1969 p. 98 e108.

${ }^{3}$ Para uma discussão mais elaborada das dinâmicas de inclusão e de exclusão nas corporaçóes de ofício de Estrasburgo, ver SONKAJÄRVI, Hanna. Qu'est-ce qu'un étranger? Frontières et identifications à Strasbourg (1681-1789). Strasbourg: Presses Universitaires de Strasbourg, 2008, esp. p. 127-156. A melhor visão de conjunto sobre a história da cidade de Estrasburgo no século XVIII é oferecida por LIVET, Georges; RAPP, Francis (Orgs.). Histoire de Strasbourg. T. 3. Strasbourg de la guerre de Trente Ans à Napoléon, 1618-1815. Strasbourg: Éditions des Dernières Nouvelles de Strasbourg, 1981. Sobre a população de Estrasburgo, ver DREYER-ROOS, Suzanne. La Population strasbourgeoise sous l'Ancien Regime, op. cit.

${ }^{4}$ No original passementier. Passamaneiro, em português, significa "fabricante ou vendedor de passamanes ou passamanaria". Por sua vez, passamanaria é uma designação comum a certos tipos de tecido trabalhado, ou entrelaçado com fio grosso, em geral de seda (passamanes, galóes, rendas, franjas, bordados, borlas etc.), destinado ao acabamento, ou adorno de roupas, cortinas, móveis etc. Ver FERREIRA, Aurélio Buarque de Holanda. Novo Dicionário Aurélio da Língua Portuguesa. 2.ed. Curitiba: Editora Positivo, 1987. Nota do Tradutor.

${ }^{5}$ Arquivos Municipais de Estrasburgo [daqui em diante, AMS], AA 2064, fl. 152, Pedido do citado Retaillons para ser aceito como fabricante de bordados em Estrasburgo. Observaçôes sobre as dificuldades dessa instalação, 1777; AMS, XI 279, Extrato do protocolo da Guilda do Espelho de 1778 a 1784, p. 174-175, le 21 juillet 1777.

${ }^{6}$ No original Tribu. Embora a autora informe, mais adiante, ser esta a designação das corporaçóes de ofício em Estrasburgo, preferimos empregar o vocábulo guilda - tradução portuguesa da palavra alemã Zünfte, modernamente, Zunft (assim como guilde é a sua tradução francesa) -, mais familiar aos pesquisadores e estudiosos dessa temática. Nota do Editor.

${ }^{7}$ No original droit de bourgeoisie. Direito do Antigo Regime que vinculava o seu titular a uma comuna, numa rede de obrigaçóes e de deveres. O direito de burguesia era obtido após um tempo de permanência na cidade, ou após o pagamento de uma taxa e implicava, na maioria das vezes, a obrigação de possuir um imóvel no local. A condição de burguês implicava alguns privilégios importantes, tais como a isenção de alguns impostos, o direito de entrar com as mercadorias e o direito de participar da vida política da cidade. Em Paris, o prazo para obter esse direito era de 1 ano e 1 dia, enquanto em Lyon, ou em Marselha, esse prazo era de 10 anos. Cf. MOURRE, Michel. Dictionnaire encyclopédique d'Histoire, op. cit. Nota do Tradutor.
\end{abstract}


${ }^{8}$ No original villes jurandes. O vocábulo jurandes pode significar guildas, mas também se refere aos juramentos prestados pelos artesãos agrupados numa corporação, ou pelos burgueses em relação à comuna. Os que se uniam numa corporação "prestavam juramento ao oficio", da mesma forma que os burgueses de uma mesma cidade "prestavam juramento à comuna”. Ao lado dos ofícios “juramentados”, sempre existiram os ofícios livres que, mesmo submetidos ao regulamento geral da comuna, ou do rei, não estavam regulamentados por um estatuto corporativo. Cada corporação tinha uma direção composta por mestres eleitos pelos seus membros chamados jurados, guardas ou síndicos dependendo da região. Esses jurados eram encarregados de controlar o cumprimento dos regulamentos do ofício; eles tinham o direito permanente de visita podendo apreender os produtos que não estivessem de acordo com as normas, impor multas, ou excluir um membro por contrafação. Cf. MOURRE, Michel. Dictionnaire encyclopédique d'Histoire, op. cit. Nota do Tradutor.

${ }^{9}$ AMS, AA 2064, fl. 152.

${ }^{10}$ HERTNER, Peter. Stadtwirtschaft zwischen Reich und Frankreich. Wirtschaft und Gesellschaft Straßburgs 1650-1714. Cologne/Vienne: Böhlau, 1973, p. 44.

11 HEITZ, Friedrich Carl. Das Zunftwesen in Straßburg. Geschichtliche Darstellung begleitet von Urkunden und Aktenstücken. Strasbourg: F.C. Heitz, 1856, p. 22.

${ }^{12}$ GREISSLER, Paul. La Classe politique dirigeante à Strasbourg, 1650-1750. Strasbourg: Le Quai, 1987, p. 23.

${ }^{13}$ Os Leibzünftigen podiam, em razão de sua atividade profissional, ser recebidos como Geldzünftig numa outra guilda, em troca de pagamento em dinheiro. Cf. HERTNER, Peter. Stadtwirtschaft zwischen Reich und Frankreich, op. cit., p. 45.

${ }^{14}$ Compagnons (companheiros, ou artesãos) eram os membros das corporaçóes de ofício que não eram mais aprendizes, mas que ainda não tinham prestado o "exame de mestria", para a obtenção do estatuto de mestre. Cf. MOURRE, Michel. Dictionnaire encyclopédique d'Histoire, op. cit.

${ }^{15}$ No original compagnonnage. A tradução literal é “companheirismo” e se refere à condição do artesão (compagnon) nas corporaçóes de ofício. Essa etapa do processo de formação podia ter uma duração mais ou menos longa dependendo da profissão. As corporaçóes previam que os compagnons, antes de abrirem o seu próprio estabelecimento, deveriam visitar os principais centros profissionais do país, trabalhando neles para o aperfeiçoamento de seus conhecimentos. Na França, a compagnonnage esteve ligada aos "tours de France" (viagens pela França), uma tradição para todos os ofícios, ainda que em algumas profissóes fosse bem restrita. Essa aprendizagem itinerante existia na maior parte da Europa, com exceçáo da Inglaterra; na Alemanha, chamava-se Wanderzwang. Cf. MOURRE, Michel. Dictionnaire encyclopédique d'Histoire, op. cit. Nota do Tradutor.

${ }^{16}$ Cf. VOGLER, Bernard. La vie économique et les hiérarchies sociales. In: LIVET, Georges; RAPP, Francis (Orgs.). Histoire de Strasbourg des origines à nos jours. T. 3. Strasbourg de la guerre de Trente Ans à Napoléon, 1618-1815. Strasbourg: Éditions des Dernières Nouvelles d'Alsace, 1981, p. 202.

${ }^{17}$ Arquivos departamentais do Baixo-Reno, Estrasburgo [a partir daqui: ABR], C 580, n48, Ordenação sobre as instruçóes e a admissão dos companheiros dos ofícios, 21 de agosto de 1743 e n63, Ordenação da polícia sobre as instruções e os portos da cidade, 15 de março de 1745 .

${ }^{18}$ Cf. HEITZ, Friedrich Carl. Das Zunftwesen in Straßburg, op. cit., p. 29-30.

${ }^{19}$ No original Tribu de l'Échasse. Pode ser traduzido como Guilda da Perna de Pau, ou seja, os integrantes dessa corporação provavelmente usavam, para seu ofício, essas peças longilíneas colocadas sob os pés para ganhar altura, feitas geralmente de madeira ou de metal. As pernas de pau se popularizaram graças ao circo e com o teatro de rua, mas, muito antes disso, tiveram diferentes usos. Na França, eram utilizadas como instrumento de trabalho pelos gesseiros. Nota do Tradutor.

${ }^{20}$ FUCHS, François-Joseph. Nouvelles sources illustrant le rayonnement artistique de Strasbourg au début du XVIIIe siècle. Extraits des procès-verbaux de la corporation de l'Échasse (1716-1724). Cahiers Alsaciens d'archéologie, d'art et d'histoire, n. 46, p. 55-85, 2003.

${ }^{21}$ Fuchs refere-se aos não-alsacianos como estrangeiros.

${ }^{22}$ Cf. FUCHS, François-Joseph. Nouvelles sources illustrant le rayonnement artistique de Strasbourg au début du XVIIIe siècle, op. cit., p. 55-56.

${ }^{23}$ O Pretor Real (no original, le Préteur royal) tinha como tarefa influenciar as decisóes do Magistrado em favor do rei. Ele assistia a todas as sessóes convocadas pelo Magistrado e mantinha correspondência direta com o Secretário do Estado e da Guerra. Dessa forma, seu papel, na prática, era duplo: ele representava o Rei na cidade e junto ao Magistrado; mas ele era também advogado da cidade junto ao Secretário de Estado e da Guerra do qual dependia diretamente. Entretanto, muitas vezes ele tomava o partido do Magistrado e dos interesses da cidade, principalmente quando havia disputas com o Intendente da Alsácia.

${ }^{24}$ Nas corporaçôes de ofício, nomeava-se chef-d'oeuvre (obra-prima) o trabalho que os companheiros executavam, no "exame de mestria”, com o objetivo de se tornarem mestres e que era avaliado por um júri. Cf. Cf. MOURRE, Michel. Dictionnaire encyclopédique d'Histoire, op. cit. Nota do Tradutor.

${ }^{25}$ AMS, AA 2065, fl. 176-177, Cópia de uma carta da Câmara dos XV ao Sr. inspetor geral das finanças, do dia 3 de novem- 
bro de 1755; AMS, AA 2065, fl. 178-182, Memorial para as comunidades de Artes e de Ofícios da cidade de Estrasburgo, do 14 de novembro de 1755 .

${ }^{26}$ Cf. VOGLER, Bernard. La vie économique et les hiérarchies sociales, op. cit., p. 218-220.

${ }^{27}$ No original Tribu des Gourmets. Nota do Editor.

${ }^{28}$ Cf. VOGLER, Bernard. La vie économique et les hiérarchies sociales, op. cit., p. 205.

${ }^{29}$ No original [Corporation des] charron: aquele que fabrica e conserta carroças, charretes e outros veículos com rodas; carpinteiro de rodas. Nota do Tradutor.

${ }^{30}$ Cf. VOGLER, Bernard. La vie économique et les hiérarchies sociales, op. cit., p. 205.

${ }^{31}$ Cf. PALLACH, Ulrich-Christian. Fonctions de la mobilité artisanale et ouvrière - compagnons, ouvriers et manufacturiers en France et aux Allemagnes (17e-19e siècles). Francia, n. 11, 1983, p. 375.

${ }^{32}$ Cf. WOLF, Karl. Der Kampf der katholischen Handwerker um Bürger - und Meisterrecht in Frankfurt a.M. gegen Ende des 18. Jahrhunderts. Historisches Jahrbuch, n. 54, p. 239-253, 1934.

33 PARISET, François. Étude sur l'atelier de la cathédrale de Strasbourg entre 1681 et 1789. Archives alsaciennes d'histoire de l'art, p. 169-207, 1929.

${ }^{34}$ Cf. LUDMANN, Jean-Daniel. La vie artistique et l'urbanisme à Strasbourg au XVIIIe siècle. In: LIVET, Georges; RAPP, Francis (Orgs.). Histoire de Strasbourg des origines à nos jours. T. 3. Strasbourg de la guerre de Trente Ans à Napoléon, 16181815. Strasbourg: Éditions des Dernières Nouvelles d'Alsace, 1981, p. 473-478.

35 A presença dos marceneiros franceses foi estudada em especial por LÉVY-COBLENTZ, Françoise. L'Art du meuble en Alsace au siècle des Lumières. T. 2. De la paix de Ryswick à la Révolution (1698-1789). Saint-Dié: Éditions Le Chardon, 1985, sobretudo p. 121-142 e LÉVY-COBLENTZ, Françoise. La position des menuisiers français dans l'affaire de leur chef-d'oeuvre à Strasbourg, en 1698. Annuaire de la Société des amis du Vieux-Strasbourg, p. 93-96, 1975.

${ }^{36}$ No original corporation de charrons. Ver nota 29. Nota do Tradutor.

${ }^{37} \mathrm{Na}$ Alemanha denomina-se Winkelarbeiter, Störer, Pfuscher, Stümple e Böhnhasen aos "falsos operários" que trabalham ilicitamente por sua própria conta. Os "franceses" não eram, aliás, os únicos a serem qualificados de "gâte-métiers" (profissionais incompetentes). Todo mestre que não respeitasse as regras da corporação era denominado dessa forma, assim como os trabalhadores não qualificados e assalariados que exerciam um ofício fora do sistema corporativo. Cf. KAPLAN, Steven L. Les corporations, les "faux ouvriers" et le Faubourg Saint-Antoine au XVIIIe siècle. Annales: Économies, Sociétés, Civilisations, n. 43, p. 353-378, 1988; LE GOFF, Jacques. Métiers licites et métiers illicites dans l’occident médiéval. In: LE GOFF, Jacques (Dir.). Pour un autre Moyen Age. Paris: Gallimard, 1978, p. 91-107.

${ }^{38}$ No original gâte-métier, cuja tradução literal é "estraga ofício". O termo pode também ser traduzido por "profissional incompetente". Nota do Tradutor.

${ }^{39}$ Cf. LÉVY-COBLENTZ, Françoise. L'Art du meuble en Alsace au siècle des Lumières, op. cit., p. 113-114.

${ }^{40}$ AMS, 2 R 102, fl. 170, Extrato do protocolo da Câmara dos XV do dia 2 de agosto de 1698.

${ }^{41}$ AMS, 2 R 102, fl. 179, Extrato do protocolo da Câmara dos XV do dia 16 de agosto 1698.

42 AMS, XI 56, Extrato do memorial da Câmara dos XV, do dia 23 de outubro de 1698.

43 AMS, 2 R 102, fl. 307, Extrato do protocolo da Câmara dos XV do dia 13 de dezembro de 1698; fl. 301-303, e do dia 12 de dezembro de 1698.

${ }^{44} \mathrm{O}$ ofício do Síndico Real foi criado em 9 de novembro de 1681 com a função de zelar pelos interesses do rei junto ao Magistrado. A importância dessa função diminuiu com a criação do cargo de Pretor Real, em maio de 1685, e levou a uma disputa pelo poder entre os titulares dessas duas funçóes. O cargo de Síndico foi abolido em 1718 e reintroduzido no período entre 1752 e 1781. Cf. STREITBERGER, Ingeborg. Der Königliche Prätor von Straßburg, 1685-1789. Wiesbaden: Steiner, 1961.

${ }^{45}$ Cf. LÉVY-COBLENTZ, Françoise. Enquête sur le mobilier de la cathédrale de Strasbourg de sa restitution au culte catholique aux travaux de G. Klotz (1681-1880), (2). Annuaire de la Société des amis du Vieux-Strasbourg, n. 7, p. 53-78, 1977 , p. 56.

${ }^{46}$ Os quatro primeiros foram Claude Bourdy, de Lyon; Pierre Lizant (ou Luysan ou Lisan), de Rouen; Jacques Bergerat, de Dienville, perto de Troyes na Champagne; e Jean Guernetot (conhecido pelo nome de St-Germain, ou François St-Jean), de Rouen. Os outros quatro eram Roger Collot, de Noyers na Bourgogne; Pierre Duperray, de Paris; Jean Guillemain, de Belfort; e Jean Richard, de Paris.

${ }^{47}$ Cf. LÉVY-COBLENTZ, Françoise. Enquête sur le mobilier de la cathédrale de Strasbourg de sa restitution au culte catholique aux travaux de G. Klotz (1681-1880), op. cit., p. 94-96.

${ }^{48}$ AMS, 2 R 105, fl. 148, Extrato do protocolo da Câmara dos XV do dia 15 de abril de 1701; AMS, 2 R 107, fl. 227-228, Extrato do protocolo da Câmara dos XV do dia 7 de setembro de 1703. 
${ }^{49}$ Cf. LÉVY-COBLENTZ, Françoise. L’Art du meuble en Alsace au siècle des Lumières, op. cit., p. 123-124.

${ }^{50}$ De forma semelhante, os exames de mestria - tanto o alemão, quanto o francês - dos seleiros continuaram em conflito mesmo após a constituição de duas corporaçóes distintas.

${ }^{51}$ AMS, XI 38, Extrato do protocolo da Câmara dos XV, do dia 20 de fevereiro de 1740.

${ }^{52}$ Cf. POLACZEK, Ernst. Das Handwerk der französischen Schreiner der Stadt Strassburg. Elsässische Monatsschrift für Geschichte und Volkskunde, n. 1, 1910, p. 322. Segundo o autor, encontram-se aí alguns filhos de burgueses, mas principalmente Suábios, Hessianos e habitantes do Palatinado. A imigração dos marceneiros franceses esgotou-se em razão das dificuldades econômicas provenientes da Guerra de Sucessão da Espanha.

${ }^{53}$ Ver os exemplos dos marceneiros protegidos pela jurisdição particular da cidadela, pelos conventos e pelos notáveis, em LÉVY-COBLENTZ, Françoise. L'Art du meuble en Alsace au siècle des Lumières, op. cit., p. 113-115. O bispo de Estrasburgo continuou, ainda, no fim do século XVIII, a empregar trabalhadores fora do sistema corporativo. AMS; AA 2623, fl. 103-104, Reclamaçóes dos pedreiros e talhadores de pedras, que trabalharam no seminário, contra sua exclusão da caixa de seguros da Guilda dos Pedreiros, s.d. [1785/1786].

${ }^{54}$ Cf. LÉVY-COBLENTZ, Françoise. L'Art du meuble en Alsace au siècle des Lumières, op. cit., p. 235.

${ }^{55}$ A importância da religiāo já foi salientada por POLACZEK, Ernst. Das Handwerk der französischen Schreiner der Stadt Strassburg, op. cit., p. 321-330.

${ }^{56}$ A Coroa adotou uma estratégia ofensiva e renunciou à proibição dos casamentos mistos, em 1774, com o objetivo de permitir a inserção dos católicos na elite local. Tal decisão já havia sido sugerida pelo cardeal Louis-Constantin de Rohan, em 1759. Cf. SONKAJÄRVI, Hanna. Qu'est-ce qu'un étranger? Op. cit., p. 114-116.

${ }^{57}$ Cf. CHÂTELLIER, Louis. Tradition chrétienne et renouveau catholique dans le cadre de l'ancien diocèse de Strasbourg (16501770). Paris: Ophrys, 1981, p. 322.

${ }^{58}$ ABR, 3 J 45, Extrato dos Registros do Conselho de Estado do Rei, do dia 4 de julho de 1767.

${ }_{59}$ Peter Hertner, em Stadtwirtschaft zwischen Reich und Frankreich, op. cit., p. 67, data de 1650. A Guilda da Âncora conheceu, no período da segunda metade do século XVIII, graves problemas econômicos ligados à queda maciça dos transportes devido aos pedágios, ao contrabando, à concorrência dos camponeses que faziam pequenos transportes, ao melhoramento dos transportes terrestres e, sobretudo às contestaçóes, desde 1681, ao monopólio de navegação dos barqueiros estrasburgueses, pelo marquesado de Baden e pelo Palatinado. Cf. KOENIG, Claude. Navigation et traités concernant la navigation sur le Rhin au XVIIIe siècle. Contribution à l'étude des relations entre Versailles, Strasbourg et les cours rhénanes (1681-1790). Revue d'Alsace, n. 105, p. 95-116, 1979.

${ }^{60}$ Cf. HERTNER, Peter. Stadtwirtschaft zwischen Reich und Frankreich, op. cit., p. 67-68.

${ }^{61}$ AMS, VI 680 n¹6, Cópia da carta do Pretor Real Gayot ao Sr. Duque de Choiseul, do dia 24 de abril de 1767.

${ }^{62}$ ABR, 3 J 45, Extrato dos Registros do Conselho de Estado do Rei, do dia 4 de julho de 1767.

${ }^{63}$ AMS, 2 R 193, Registros da Câmara dos XV, do dia 10 de maio de 1783, p. 217-222.

${ }^{64}$ AMS, AA 2081, fl. 138-139. Carta do Stettmeistre de Burlach sobre a Alternativa que deveria ser observada, no caso das eleiçôes na corporação dos barqueiros. - Agravos produzidos, sobre esse assunto, pelos barqueiros católicos, do dia 4 de abril de 1783. À frente do Magistrado havia quatro Stettmeister, nobres eleitos por dois anos e que exerciam a função, em alternância, um trimestre por ano. Seu papel - o de representar o Magistrado - era, sobretudo honorífico.

${ }^{65}$ Para uma visão mais dinâmica acerca das corporaçóes, ver, entre outros, os estudos de CERUTTI, Simona. La Ville et les métiers. Naissance d'un langage corporatif (Turin, XVIIe-XVIIIe siècle). Paris: Éditions de l'École des Hautes Études en Sciences Sociales, 1991; KAPLAN, Steven L. La lutte pour le contrôle du marché du travail à Paris au XVIIIe siècle. Revue d'Histoire Moderne et Contemporaine, n. 36, p. 361-412, 1989; MINARD, Philippe. Die Zünfte in Frankreich am Ende des 18. Jahrhunderts: Analyse ihrer Abschaffung. In: HAUPT, Heinz-Gerhard (Org.). Das Ende der Zünfte. Ein europäischer Vergleich. Gottingue: Vandenhoeck \& Ruprecht, 2002, p. 181-197. Sobre Estrasburgo na Idade Média, ver HEUSINGER, Sabine von. Die Zünfte im Mittelalter. Zur Verflechtung von Politik, Wirtschaft und Gesellschaft in Straßburg. Stuttgart: Franz-Steiner-Verglag, 2009, que examina as corporaçôes de ofício de Estrasburgo, a partir da análise das suas redes.

${ }^{66}$ Preferimos manter a palavra no original. Pouco utilizada no francês atual, significava o artesão que não pertencia a nenhuma corporação e trabalhava em sua própria casa, mais ou menos, às escondidas. Nota do Editor.

${ }^{67}$ No original créneaux, cuja tradução literal é "intervalo disponível entre dois espaços ocupados". Nota do Editor.

${ }^{68}$ Cf. SIMONTON, Deborah. A History of European Women's Work: 1700 to the Present. Londres/New York: Routledge, 1998.

${ }^{69}$ PFISTER, Christian. L'Alsace et l'Edit de Nantes. Revue Historique, n. 160, 1929, p. 229.

${ }^{70}$ Cf. FRANÇOIS, Étienne. Koblenz im 18. Jahrhundert. Zur Sozial - und Bevölkerungstruktur einer deutschen Residenzstadt. Gottingue: Vandenhoeck \& Ruprecht, 1982, p. 191. 
Referências bibliográficas

CERUTTI, Simona. La Ville et les métiers. Naissance d'un langage corporatif (Turin, XVIIe-XVIIIe siècle). Paris: Éditions de l'École des Hautes Études en Sciences Sociales, 1991.

CHÂTELLIER, Louis. Tradition chrétienne et renouveau catholique dans le cadre de l'ancien diocèse de Strasbourg (1650-1770). Paris: Ophrys, 1981.

DREYER-ROOS, Suzanne. La Population strasbourgeoise sous l'Ancien Regime. Strasbourg: Istra, 1969.

FERREIRA, Aurélio Buarque de Holanda. Novo Dicionário Aurélio da Língua Portuguesa. 2.ed. Curitiba: Editora Positivo, 1987.

FRANÇOIS, Étienne. Koblenz im 18. Jahrhundert. Zur Sozial - und Bevölkerungstruktur einer deutschen Residenzstadt. Gottingue: Vandenhoeck \& Ruprecht, 1982.

FUCHS, François-Joseph. Nouvelles sources illustrant le rayonnement artistique de Strasbourg au début du XVIIIe siècle. Extraits des procès-verbaux de la corporation de l'Échasse (1716-1724). Cahiers Alsaciens d'archéologie, d'art et d'histoire, n. 46, p. 55-85, 2003.

GREISSLER, Paul. La classe politique dirigeante à Strasbourg, 1650-1750. Strasbourg: Le Quai, 1987. HEITZ, Friedrich Carl. Das Zunftwesen in Straßburg. Geschichtliche Darstellung begleitet von Urkunden und Aktenstücken. Strasbourg: F.C. Heitz, 1856.

HERTNER, Peter. Stadtwirtschaft zwischen Reich und Frankreich. Wirtschaft und Gesellschaft Straßburgs 1650-1714. Cologne/Vienne: Böhlau, 1973.

HEUSINGER, Sabine von. Die Zünfte im Mittelalter. Zur Verflechtung von Politik, Wirtschaft und Gesellschaft in Straßburg. Stuttgart: Franz-Steiner-Verglag, 2009.

KAPLAN, Steven L. La lutte pour le contrôle du marché du travail à Paris au XVIIIe siècle. Revue d'Histoire Moderne et Contemporaine, n. 36, p. 361-412, 1989.

. Les corporations, les "faux ouvriers" et le Faubourg Saint-Antoine au XVIIIe siècle. Annales: Économies, Sociétés, Civilisations, n. 43, p. 353-378, 1988.

KOENIG, Claude. Navigation et traités concernant la navigation sur le Rhin au XVIIIe siècle. Contribution à l'étude des relations entre Versailles, Strasbourg et les cours rhénanes (1681-1790). Revue d'Alsace, n. 105, p. 95-116, 1979.

LE GOFF, Jacques. Métiers licites et métiers illicites dans l'occident médiéval. In: LE GOFF, Jacques (Dir.). Pour un autre Moyen Age. Paris: Gallimard, 1978, p. 91-107.

LÉVY-COBLENTZ, Françoise. Enquête sur le mobilier de la cathédrale de Strasbourg de sa restitution au culte catholique aux travaux de G. Klotz (1681-1880), (2). Annuaire de la Société des amis du Vieux-Strasbourg, n. 7, p. 53-78, 1977.

. L'Art du meuble en Alsace au siècle des Lumières. T. 2. De la paix de Ryswick à la Révolution (1698-1789). Saint-Dié: Éditions Le Chardon, 1985.

. La position des menuisiers français dans l'affaire de leur chef-d'oeuvre à Strasbourg, en 1698. Annuaire de la Société des amis du Vieux-Strasbourg, p. 93-96, 1975.

LIVET, Georges; RAPP, Francis (Orgs.). Histoire de Strasbourg. T. 3. Strasbourg de la guerre de Trente Ans à Napoléon, 1618-1815. Strasbourg: Éditions des Dernières Nouvelles de Strasbourg, 1981.

LUDMANN, Jean-Daniel. La vie artistique et l'urbanisme à Strasbourg au XVIIIe siècle. In: LIVET, 
Georges; RAPP, Francis (Orgs.). Histoire de Strasbourg des origines à nos jours. T. 3. Strasbourg de la guerre de Trente Ans à Napoléon, 1618-1815. Strasbourg: Éditions des Dernières Nouvelles d'Alsace, 1981, p. 459-532.

MINARD, Philippe. Die Zünfte in Frankreich am Ende des 18. Jahrhunderts: Analyse ihrer Abschaffung. In: HAUPT, Heinz-Gerhard (Org.). Das Ende der Zünfte. Ein europäischer Vergleich. Gottingue: Vandenhoeck \& Ruprecht, 2002, p. 181-197.

MOURRE, Michel. Dictionnaire encyclopédique d'Histoire. Paris: Larousse-Bordas, 1998.

PALLACH, Ulrich-Christian. Fonctions de la mobilité artisanale et ouvrière - compagnons, ouvriers et manufacturiers en France et aux Allemagnes (17e-19e siècles). Francia, n. 11, p. 365-406, 1983.

PARISET, François. Étude sur l'atelier de la cathédrale de Strasbourg entre 1681 et 1789. Archives alsaciennes d'histoire de l'art, p. 169-207, 1929.

PFISTER, Christian. L'Alsace et l'Edit de Nantes. Revue Historique, n. 160, p. 217-240, 1929.

POLACZEK, Ernst. Das Handwerk der französischen Schreiner der Stadt Strassburg. Elsässische Monatsschrift für Geschichte und Volkskunde, n. 1, p. 321-330, 1910.

SIMONTON, Deborah. A History of European Women's Work: 1700 to the Present. Londres/New York: Routledge, 1998.

SONKAJÄRVI Hanna. Qu'est-ce qu'un étranger? Frontières et identifications à Strasbourg (1681-1789). Strasbourg: Presses Universitaires de Strasbourg, 2008.

STREITBERGER, Ingeborg. Der Königliche Prätor von Straßburg, 1685-1789. Wiesbaden: Steiner, 1961.

VOGLER, Bernard. La vie économique et les hiérarchies sociales. In: LIVET, Georges; RAPP, Francis (Orgs.). Histoire de Strasbourg des origines à nos jours. T. 3. Strasbourg de la guerre de Trente Ans à Napoléon, 1618-1815. Strasbourg: Éditions des Dernières Nouvelles d'Alsace, 1981, p. 187-254.

WOLF, Karl. Der Kampf der katholischen Handwerker um Bürger - und Meisterrecht in Frankfurt a.M. gegen Ende des 18. Jahrhunderts. Historisches Jahrbuch, n. 54, p. 239-253, 1934. 